\title{
TRADUÇÃO
}

\section{Introdução à tradução: sobre a formulação do conceito crítico de liberdade e de autonomia da vontade}

Diego Kosbiau Trevisan

Doutorando em Filosofia pela USP

O que o leitor terá na sequência é a tradução de uma pequena seleção de reflexões de Immanuel Kant sobre filosofia moral redigidas, em sua grande maioria, ao longo "década silenciosa" de 1770. A escolha dos fragmentos, retirados dos volumes XVII, XVIII (Reflexões sobre Metafísica) e XIX (Reflexões sobre Filosofia Moral) da edição da Academia, ${ }^{1}$ foi motivada por um interesse interpretativo de fundo: a defesa de uma descontinuidade da filosofia moral kantiana na passagem do período pré-crítico para o crítico. Com isso se sugere que a existência de uma concepção crítica da liberdade e a formulação do princípio da autonomia da vontade como um princípio supremo da moralidade apenas se tornaram possíveis após a Dissertação de 1770 . O princípio norteador para a escolha das reflexões traduzidas para este volume dos Cadernos de Filosofia Alemã foi o de mostrar, ainda que de modo rudimentar, o despontar conceitual mais bem acabado desses dois elementos conceituais centrais da filosofia prática crítica ao longo da década de 1770 .

A ideia de uma descontinuidade no pensamento kantiano em matérias de filosofia moral está longe de ser um ponto pacífico na Kant-Forschung. Não são poucos os comentadores que põem em questão a existência mesma de uma filosofia prática kantiana genuinamente crítica e influenciada pela "revolução copernicana" em filosofia desencadeada pela Crítica da Razão Pura. A célebre tese da continuidade da filosofia moral pré-crítica no período crítico foi inicialmente defendida por Dieter Henrich e depois compartilhada por, dentre outros, Josef Schmucker, e Karl-Heinz Ilting.

1. KANT, I. Gesammelte Schriften: berausgegeben von der Deutschen Akademie der Wissenschaften. 29 vols. Berlin: Walter de Gruyter, 1902 
Dieter Henrich defende que "a fórmula do imperativo categórico baseada na universalidade da vontade mesma" e as "duas primeiras seções da Fundamentação da Metafísica dos Costumes" já estariam estabelecidas por volta de 1765 nos Comentários <Bemerkungen> às Observações sobre o sentimento do belo e do sublime $e^{2}$. Segundo Henrich, o percurso sistemático interno à Fundamentação, a saber, partir da boa vontade para o imperativo categórico e a autonomia da vontade, também caracterizaria o percurso genealógico do pensamento kantiano em filosofia prática. A "intuição" kantiana de 1765 , segundo a qual a boa vontade seria a vontade despida de interesses particulares, já conteria os elementos necessários para ser denominada "crítica": o quase presságio que levou a uma, por assim dizer, "intuitiva" formulação do imperativo categórico já no ano de 1765 fundaria a concepção da autonomia da vontade como fundamento de possibilidade de uma boa vontade ${ }^{3}$. Josef Schmucker também argumenta que o conteúdo da futura filosofia prática crítica já estaria contido in nuce nos escritos redigidos por Kant entre 1764 e 1766; da mesma maneira, o problema formal da determinação da vontade unicamente pela lei moral de que trata a Fundamentação da Metafísica dos Costumes e a Crítica da Razão Prática em nada dependeria da Crítica da Razão Pura e da nova démarche crítica ${ }^{4}$. Por

2. HENRICH, D. "Kant and Hutcheson". In: AMERIKS, K \& HÖFFE, O. (orgs). Kant's Moral and Legal Pbilosopby. Cambridge: Cambridge University Press, 2009. pp. 51-52. O original é de 1957: "Hutcheson und Kant". In: Kant-Studien, 49, 1957-1958. Cf. também. Idem."Ethics of Autonomy" In: The Unity of Reason. Cambridge \& London: Harvard University Press, 1994. p. 98; O original é de 1963: "Das Problem der Grundlegung der Ethik bei Kant und im spekulativen Idealismus". In: Sein Und Ethos: Walberger Studien, vol 1. Mainz. E Idem. "Über Kants früheste Ethik". In: Kant-Studien 54. 1963.

3. A "intuição" de 1765 "funda também a concepção de uma 'autonomia da vontade', e, de fato, de tal modo que esta se apresenta como o conceito da possibilidade de uma vontade boa por si mesma. O desenvolvimento tardio de Kant constitui-se como uma sucessão de tentativas de desenvolver o conceito dos bens específicos da vontade <der besonderen Güten des Willens> (...). O caminho que, na Fundamentação da Metafísica dos Costumes, conduz do conceito de uma vontade absolutamente boa à fórmula do imperativo categórico e depois à doutrina da autonomia da vontade, foi também o caminho histórico da ética kantiana". HENRICH, D. "Über Kants früheste Ethik". p. 406.

4. Segundo Schmucker, "temos claro este tipo de crítica da razão prática já em Crusius e Hutcheson e no Kant mesmo na Investigação sobre a evidência dos princípios da teologia natural e da moral, nas Observações sobre o sentimento do belo e do 
fim, Karl-Heinz Ilting busca rebater a contratese de Werner Busch, para quem haveria um conceito crítico de liberdade formulado a partir de 1772 que marcaria o início da filosofia prática crítica ${ }^{5}$, argumentando que Kant, na verdade, retém uma concepção dogmática de liberdade desde 1765 que em nada dependeria da nova visada crítico-transcendental desenvolvida ao longo da década de 70 e que encontra seu acabamento no período posterior à Crítica da Razão Pura .

Nesse breve texto introdutório certamente não é possível retomar em toda sua profundidade o debate em torno desse ponto polêmico do desenvolvimento do pensamento kantiano. Entrariam na discussão controversas questões a respeito do que seriam as marcas definidoras do caráter crítico e transcendental da filosofia prática-e, decerto, da filosofia teórica - de Kant, dos grandes movimentos percebidos no interior da evolução de seu pensamento, daquilo

sublime, nos Comentáriosàs Observações sobre o sentimento do belo e do sublime e nos Sonbos de um visionário; trata-se de um problema bem próprio da doutrina ética dos princípios e não permanece nem genética nem fatualmente <sachlich> em uma relação de dependência com o problema crítico da metafísica teórica". SCHMUCKER, J. Die Ursprunge der Etbik Kants. Meisenheim am Glan: Verlag Anton Hain Kg. 1961. p. 383.

5. BUSCH, W. Die Entstebung der kritischen Rechtspbilosophie Kants. Berlin/New York: De Gruyter, 1979. pp. 70ss. Este conceito crítico de liberdade consistiria em tomar o homem como um ser natural e racional, ou seja, como um agente que produz efeitos no mundo sensível cuja causa, contudo, não pode ser atribuída a estímulos que provêm deste mesmo mundo sensível. Em suma, trata-se, grosso modo, da questão liberdade como espontaneidade e oposta ao determinismo natural de que trata a terceira antinomia da Crítica da Razão Pura.

6. Segundo Ilting, "não se reconhece uma 'virada crítica' de Kant nos anos setenta no âmbito da filosofia prática (...). Kant, mesmo nos escritos sobre filosofia prática dos anos oitenta, ainda se apóia na doutrina de uma metafísica pré-crítica e, logo lá onde conecta problemas éticos com sua crítica da razão, afasta-se daquilo que com direito poder-se-ia chamar de uma ética e filosofia do direito críticas". ILTING, K-H. Gibt es eine kritische Ethik und Rechtsphilosophie Kants?. Archiv für Geschichte der Philosophie. Vol. 63, n. 3, 1981. p. 325. O "conceito dogmático" de liberdade a que Ilting se refere seria aquele exposto no fragmento "Sobre a Liberdade" dos Comentários às Observações sobre o sentimento do belo e do sublime (Ak XX: 91-94). Segundo Ilting, a ideia discutida no fragmento acerca de uma liberdade "natural" como não submissão ao arbítrio alheio definiria a liberdade como um "direito fundamental" do homem, e, portanto, haveria já em 1765 uma dimensão de dignidade que prefigura a concepção "crítica" de liberdade. 
que caracteriza e define as principais etapas de descompasso e os claros momentos de ruptura na Entstebungsgeschichte da Crítica da Razão Pura e as interconexões conceituais entre a filosofia prática e teórica observadas no período, para não mencionar, enfim, as inúmeras mudanças por que passou o sistema kantiano no decorrer do próprio período crítico $^{7}$. No entanto, assumimos que os dois pontos mencionados no parágrafo inicial bastam para que se atinja um "mínimo conceitual" que define os traços elementares da filosofia moral do período crítico: uma complexa concepção de liberdade conforme exposta na $3^{\mathrm{a}}$ antinomia da Crítica da Razão Pura, na Fundamentação, na Crítica da Razão Prática e na Metafísica dos Costumes, e o princípio da autonomia da vontade como princípio supremo da filosofia moral - esses dois eixos conceituais tornam possíveis não apenas a fundamentação crítica da filosofia prática de Kant como também a divisão de seu sistema em uma Doutrina do Direito e uma Doutrina da Virtude, realizada na Metafísica dos Costumes de 1797.

Uma análise detida do material postumamente recolhido nos volumes X a XXIX da edição da Academia - as correspondências, o "legado manuscrito" (bandschriftliche Nacblass) e as anotações de cursos feitas por alunos de Kant - mostra que apenas a partir do fim da década de $60^{8}$ surge a explícita recusa ao sentimento moral e aos princípios

7. Para uma discussão a respeito de alguns desses últimos pontos, remetemos o leitor à nossa dissertação de mestrado: TREVISAN, D. K. A Metafísica dos Costumes. A Autonomia para o Ser Humano. Dissertação de Mestrado. Faculdade de Filosofia Letras e Ciências Humanas. Departamento de Filosofia, Universidade de São Paulo, 2011.

8. Ao afirmar isso, passamos por cima dos problemas de datação das Reflexionen coligidas na Akademie Ausgabe por Adickes, problemas, de resto, amplamente conhecidos e discutidos na Kant-Forscbung. Alguns dos critérios empregados, a saber, a tinta utilizada, a caligrafia, a condição do papel no qual está anotada a reflexão, são, decerto, duvidosos - apenas em poucos casos a datação do manuscrito é mais segura, como, por exemplo, quando há algo anotado em cartas que trazem uma data precisa (cf. introdução do próprio Adickes à sua compilação, Ak XIV: xxviii-Xxxv). Ademais, as Schriftphasen, ou seja, os intervalos de tempo selecionados para a classificação do material, compreendem, em muitos casos, um período extenso e, assim, aumentam a incerteza quanto à data precisa em que foi redigida determinada reflexão, diversas vezes classificada como possivelmente pertencente a mais de uma Schriftphase (cf. Ak XIV: xxxvi-xliii). Sobre os problemas (e méritos, em comparação às tentativas anteriores de Erdmann, Haering e Reicke) do procedimento de 
Introdução à tradução: sobre a formulação do conceito crítico de liberdade...

racionalistas como bases da moral e, nesta esteira, fazem-se notar a autonomização da filosofia prática em relação à teórica, o surgimento da complexa concepção crítica da liberdade e o despontar inicial do princípio da autonomia como exigência normativa suprema da filosofia prática crítica e fundamento para o tratamento sistemático dos deveres na Metafísica dos Costumes. O caminho em que Kant se envereda na busca por um princípio incondicionado da moral passa necessariamente pela razão pura como determinante da ação livre segundo uma prescrição não tautológica ou vazia e não dependente de algum sentimento físico ou moral. As reflexões do período traduzidas aqui dão mostra de que Kant pensava a obrigação moral, incondicionada e imediatamente vinculante, lançando mão de um modelo - de inspiração eminentemente jurídica - de uma comunidade de seres racionais unificados ou harmonizados por meio de um nexo entre lei prática, liberdade, universalidade e origem na razão pura depurada de elementos empíricos. O princípio da moralidade e a concepção positiva de liberdade começam a delinear-se nesse período da evolução do pensamento de Kant como o princípio de autonomia que encontraria seu lugar central na história da filosofia moral e que até hoje exerce decisiva influência em diversas áreas do pensamento filosófico contemporâneo.

Dividimos as reflexões em três grandes blocos que refletem a preocupação interpretativa discutida acima. O primeiro reúne reflexões que gradualmente sinalizam a cristalização da solução kantiana para o problema de fundamentação de uma filosofia moral: as bases da

Adickes, cf, p.ex, KLEMME, H. Kants Pbilosopbie des Subjekts. Hamburg: Felix Meiner, 1996. pp. 40-41. VLEESCHAUWER, H.J. La Déduction Transcendentale dans l'Oeuvre de Kant. Tome I. New York \& London: Garland Publishing, Inc, 1976. Reeimpressão de Antwerpen: De Sikkel, 1934. Pp. 43-49. Notemos, pois, que a análise que propomos aqui tem de se apoiar não apenas no material póstumo, cronologicamente impreciso, como também nas obras publicadas por Kant na década de 1760, para o que remetemos o leitor uma vez mais à nossa dissertação (TREVISAN, D. K. A Metafísica dos Costumes. A Autonomia para o Ser Humano); ademais, dado que a indeterminação temporal das Reflexionen atinge as interpretações acima discutidas, entendemos que nossa própria interpretação fica assim resguardada de possíveis críticas quanto à sua imprecisão cronológica, ao menos de críticas vindas da linha dos intérpretes a que aqui nos opomos. 
obrigação e do dever devem ser buscadas na atividade pura da razão, em sua capacidade autônoma de legislar sem influência de elementos privados e particularistas que impediriam a universalidade buscada para o princípio moral. No segundo bloco, o problema da liberdade é analisado no interior da perspectiva estabelecida pela Dissertação de 1770 e da distinção entre um mundo sensível e um mundo inteligível retomada e retrabalhada ao longo do período crítico. No terceiro bloco, por fim, as reflexões traduzidas abordam as distinções entre direito e ética e sugerem a forte matriz jurídica presente na estrutura de pensamento que dá origem à filosofia prática crítica: a ideia de que a elaboração do princípio jurídico - em que a influência da vontade geral de Rousseau faz-se decisivamente presente - constitui um incentivo heurístico para a elaboração do princípio supremo da moral e, com isso, para o conceito positivo de liberdade como autonomia. Conscientes de que o número de reflexões selecionadas é insuficiente para que a interpretação delineada acima encontre um apoio conceitual consistente, a tradução apresentada pode ser mais bem caracterizada como um convite para que que o próprio leitor se volte às fontes indicadas e para que seja lançada a devida atenção a esse manancial interpretativo da filosofia de Kant ainda não plenamente explorado nos estudos kantianos brasileiros.

\section{Referências bibliográficas}

BUSCH, W. Die Entstebung der kritischen Rechtspbilosopbie Kants. Berlin/New York: De Gruyter, 1979.

HENRICH, D. Ethics of Autonomy. In: The Unity of Reason. Cambridge \& London: Harvard University Press, 1994. Orig.: Das Problem der Grundlegung der Ethik bei Kant und im spekulativen Idealismus. In: Sein Und Ethos. Walberger Studien, vol 1: Mainz. 1963.

Kant and Hutcheson. In: Ameriks, K \& Höffe, O. (orgs). Kant's Moral and Legal Pbilosopby. Cambridge: Cambridge University Press, 2009. Orig.: Hutcheson und Kant. In: Kant-Studien, 49, 1957-1958. Über Kants früheste Ethik. In: Kant-Studien 54. 1963.

ILTING, K-H. Gibt es eine kritische Ethik und Rechtsphilosophie Kants?. In: Arcbiv für Geschicbte der Pbilosopbie. Vol. 63, N. 3, 1981.

KANT, I. Gesammelte Schriften: berausgegeben von der Deutschen Akademie der Wissenschaften. 29 vols. Berlin: Walter de Gruyter, 1902- 
Introdução à tradução: sobre a formulação do conceito crítico de liberdade...

KLEMME, H. Kants Pbilosopbie des Subjekts. Hamburg: Felix Meiner, 1996.

RITTER, C. Der Recbtsgedanke Kants nacb den früben Quellen. Frankfurt: Vittorio Klostermann, 1971

SCHMUCKER, J. Die Ursprunge der Ethik Kants. Meisenheim am Glan: Verlag Anton Hain Kg. 1961.

TREVISAN, D. K. A Metafísica dos Costumes. A Autonomia para o Ser Humano. Dissertação de Mestrado. Faculdade de Filosofia Letras e Ciências Humanas. Departamento de Filosofia, Univer-sidade de São Paulo, 2011.

VLEESCHAUWER, H.J. La Déduction Transcendentale dans l'Oeuvre de Kant. Tome I. New York \& London: Garland Publishing, Inc, 1976. Reeimpressão de Antwerpen: De Sikkel, 1934. 
Immanuel Kant

\section{Reflexões sobre filosofia moral da década de $\mathbf{1 7 7 0}$}

Immanuel Kant

1) Universalidade, racionalidade e formalismo

Rx 6598 Ak XIX: 103. 1769-1770 (1764-1768?)

Die Mittel sind nur die Form der intention oder die Methode der Ausführung, der Zwek ist die Materie. Handlungen sind den Mitteln nach oder dem Zwek nach Vernünftig; im ersteren falle determinirt die Vernunft die Form, im Zweiten auch die Materie der Absicht.

Verstand ist nur mittelbar Gut, als ein Mittel zu anderm Guten oder zur Glükseeligkeit. Das unmittelbare Gute kan nur bey der Freyheit angetroffen werden. Denn weil die freyheit ein Vermögen ist zu handeln, ob es gleich uns nicht vergnügt: so hat es ist sie nicht an die Bedingung eines Privatgefühls gebunden; da sie aber gleichwohl immer nur auf das geht, was da beliebt, so hat es ein Verhältnis aufs Gefühl und kan ein allgemein gültiges Verhältnis haben auf das Gefühl überhaupt. Daher nichts einen absoluten Werth hat als Persohnen, und dieser besteht in der bonitaet ihrer freyen Willkühr. Gleich wie die freyheit den ersten Grund von allem enthält, was anfängt, so ist sie auch, was die Selbstandige bonitaet allein enthalt.

Das moralische Gefühl ist kein ursprünglich Gefühl. Es beruhet auf einem nothwendigen inneren Gesetze, sich selber aus einem äußerlichen Standpunkt zu betrachten und zu empfinden. Gleichsam in der Persöhnlichkeit der Vernunft: da man sich im allgemeinen fühlt und sein individuum als ein Zufellig subiect wie ein accidens des allgemeinen ansieht

Rx 6610. Ak XIX: 107. 1769-1770; (1764-1768?) (extrato parcial)

Die Sittlichkeit ist eine obiective Abhängigkeit Unterordnung des Willens unter die Bewegungsgründe der Vernunft. Die Sinnlichkeit (practice) eine subordinatio des Willens unter die Neigung [...]. 


\title{
Reflexões sobre filosofia moral da década de 1770
}

\author{
Immanuel Kant
}

\section{1) Universalidade, racionalidade e formalismo}

Rx 6598 Ak XIX: 103. 1769-1770 (1764-1768?)

Os meios são apenas a forma da intenção ou o método de execução, o fim é a matéria. Ações são racionais segundo os meios ou segundo os fins; no primeiro caso, a razão determina a forma, no segundo, também a matéria da intenção.

O entendimento é apenas mediatamente bom, como um meio para outros bens ou para a felicidade. $\mathrm{O}$ imediatamente bom somente pode ser encontrado na liberdade. Pois, uma vez que a liberdade é uma faculdade de agir, mesmo se isso não nos atrai, ela então não está ligada à condição de um sentimento privado; visto que, contudo, ela não obstante sempre se refere ao que é desejado, isto então tem uma relação com o sentimento e pode ter uma relação universalmente válida com o sentimento em geral. Portanto, nada tem um valor absoluto senão pessoas, e este consiste na bondade de seu arbítrio livre. Assim como a liberdade contém o primeiro fundamento de tudo o que se inicia, ela é também o que a bondade independente unicamente contém.

O sentimento moral não é nenhum sentimento originário. Ele repousa numa lei interna necessária de considerar-se e sentir-se a si mesmo num ponto de vista externo. Por assim dizer, na personalidade da razão, já que nós nos sentimos no universal e consideramos o individiuum, enquanto um sujeito contingente, como um accidens do universal.

Rx 6610. Ak XIX: 107. 1769-1770; (1764-1768?) (extrato parcial)

A moralidade é uma subordinação dependência objetiva da vontade sob os motivos da razão. A sensibilidade (prática) é uma subordinação da vontade sob a inclinação [...]. 
Immanuel Kant

Rx 6625. Ak XIX: 116. 1769-1770 (1764-1768?)

Alle systeme sind entweder die, so aus Vernunft, oder Gefühl die moralitaet herleiten (aus dem Zwange der Obrigkeit, und aus Gewonheit).

Die aus Vernunft: entweder der Warheit oder der Vollkomenheit (Mittelstraße der Neigungen: Aristoteles). Wolf machte den allgemeinen Nahmen der Vollkomenheit zum Grunde sie zu bestimen und nante nicht dasienige oder die Zweke-d die Bedingungen, unter welchen Handlungen und Zweke Gut sind und den Nahmen vollkomenheit verdienen.

Rx 6631. Ak XIX: 118-119. 1769-1770? (1771-1772?) (extrato parcial)

[...] Aus der idee eines allgemeingültigen Willens, nicht durch Macht, sondern durch den Grund der Einstimmung. Ursprünglicher, abgeleiteter Wille) [...].

Rx 6635. Ak XIX: 121. 1769-1770; (1764-1768?)

Alle Systeme der Moral suchen zuerst den obersten (theoretischen) Grund der sittlichen Beurtheilung, zweytens die oberste Sit wirklich moralische Regel, daraus die übrige fließen, zu finden. Was das erste betrift, so leiten sie 1. solche nicht aus allgemeinen Grundsätzen der Vernunft $\mathrm{ab}$ sondern und unters suchen mehr grund von dem, was geschieht und geurtheilt wird, als was geurtheilt werden soll, sehen also das principium morale als subrepticium an und als legem phaenomenorum. Diese machen a. Moden und Beyspiele. b. die Ehrliebe und Eigennutz zum qvell aller unserer tugendhaft scheinenden Handlungen. Sie sehen dann ieden moralischen imperativ als bedingt an sub conditione subiectiva. 2. suchen ein principium ebiectivum empiricum a. durch in zufalligen Menschlichen Gesetzen: hobbes; b. In einem besonderen triebe der Menschlichen Natur und Gefühl, oder, 3. rationale.

Rx 6698. Ak XIX: 135. 1770-1771? (1773-1775?) (1769?) (extrato parcial)

Die moralische Vorschriften gelten vor iedes vernünftige und freye Wesen, die Neigungen desselben mögen seyn, wie sie wollen. [...] 
Rx 6625. Ak XIX: 116. 1769-1770 (1764-1768?).

Todos os sistemas são ou aqueles que derivam a moralidade da razão ou [aqueles que a derivam] do sentimento (a partir da coerção das autoridades, ou a partir do hábito).

Os que [derivam] da razão: ou da verdade ou da perfeição (o meio caminho entre as inclinações: Aristóteles). Wolff fez do nome geral da perfeição o fundamento para determinar a razão, e não nomeou as condições aquilo ou os fins sob as quais ações e fins são bons ou podem servir para o nome de perfeição.

Rx 6631. Ak XIX: 118-119. 1769-1770? (1771-1772?) (extrato parcial)

[...] ([Deve-se considerar a moralidade ] a partir da ideia de uma vontade universalmente válida, não através do poder, mas sim através do fundamento da concordância. Vontade originária, derivada) [...].

Rx 6635. Ak XIX: 121. 1769-1770; (1764-1768?)

Todos os sistemas morais buscam, primeiro, encontrar o fundamento (teórico) supremo do ajuizamento moral, e, segundo, a suprema regra realmente moral da qual decorrem as demais. No que diz respeito ao primeiro, [há sistemas que] derivam 1. essa regra não de princípios universais da razão, buscando mais o fundamento naquilo que acontece e que é julgado do que o que deve ser julgado; eles consideram, portanto, o principium morale como subrepticium e como legem phaenomenorum. Eles fazem a) dos usos e exemplos, b) do amor à honra e do egoísmo fontes de todas as nossas ações aparentemente virtuosas. Eles consideram, portanto, cada imperativo moral como condicionado sub conditione subjectiva. 2. [Sistemas que] buscam um principium ebiectivum empiricum [a)] oque em leis humanas contingentes: Hobbes; [b)] em um impulso particular da natureza e do sentimento humanos.

Ou 3. [sistemas que são] racionais.

Rx 6698. Ak XIX: 135. 1770-1771? (1773-1775?) (1769?). (extrato parcial)

As prescrições morais valem para todos os seres racionais e livres, sejam quais forem as inclinações que eles possam ter. [...] 
Immanuel Kant

Rx 6725 Ak XIX: 141-142. 1772

Die Gantze Schwierigkeit bey dem Streit über das principium der moral ist: wie ein apodictischer categorischer imperativus möglich sey, der nicht conditional ist, weder sub conditione problematica noch apodictica (der Geschiklichkeit. Klugheit). Ein Solcher imperativus sagt, was ursprünglich, primitive gut ist. Es ist zu bewundern, daß das primitive Gut: die condition von allem, was gefällt, nur einem Willen zukome. Die Ursache ist, weil alle Vollkomenheit eine idee und die Wirklichkeit derselben einen Willen voraus setzt, und weil alles Zufallige und aller Ursprung sich auf Freyheit gründet. Alle Nothwendigkeit der Urtheile gründet sich auf die Allgemeinheit oder diese auf jene. Mithin ist der Grund der nothwendigkeit, welche moralische Sätze enunciiren, in der allgemeingültigkeit der Gründe des Wollens zu setzen (schlechthin nothwendig, absolute, bedeutet nicht innerlich, sondern überhaupt nothwendig).

Rx 6760. Ak XIX: 151. 1772. (extrato parcial)

Das principium der moralischen dijudication

1. ist nicht der göttliche Wille $[\ldots]$,

2. nicht der allgemeine Begriff der Vollkommenheit.

3. nicht der allgemeine Begriff der de Glükseeligkeit.

4. nicht die privatglükseeligkeit (sie wären empirisch)

5. nicht das moralische Gefühl und Geschmak (Geschmak ist relativisch in 3 . Verhältnis aufs subject).

6. sondern vernunft.

Rx 6762 Ak XIX: 153. 1772

Was nicht unter einer allgemeinen Regel des reinen Willens stehen kan, ist moralisch unrichtig. Die Übereinstimung der freyen willkühr Handlung mit der allgemeinheit des reinen Willens ist Moralitaet.

Rx 6765 Ak XIX: 154-155. 1772? 1778?

Die Handlung, deren intention, als allgemeine Regel betrachtet, sich selbst und andrer ihrer nothwendig wiederstreiten würde, ist moralisch unmöglich.

Die Gesinnung, sich in seinen Handlungen dem allgemeinen principio der regeln gemäß zu verhalten, ist moralisch. Wenn der Wille der form des Verstandes überhaupt unterworfen ist. 
Rx 6725 Ak XIX: 141-142. 1772.

A grande dificuldade no conflito sobre o principium da moral é: como é possível um imperativus categórico apoditice que não seja condicional nem sub conditione problematica nem apodictica (da habilidade. Prudência). Tal imperativo diz o que é bom originariamente, primitive. É surpreendente que o bom primitivo, a condição de tudo que agrada, apenas diga respeito a uma vontade. A causa é que toda perfeição pressupõe uma ideia e a sua realidade pressupõe uma vontade, e que todo contingente e toda origem fundam-se na liberdade. Toda necessidade dos juízos funda-se na universalidade ou esta naquela. Portanto, o fundamento da necessidade que as proposições morais enunciam deve ser posto na validade universal dos fundamentos do querer (o que é totalmente, absolutamente necessário não significa internamente necessário, mas necessário em geral).

Rx 6760. Ak XIX: 151. 1772. (extrato parcial)

O principium do ajuizamento moral

(1) não é a vontade divina [...],

(2) não é o conceito universal de perfeição.

(3) não é o conceito universal de felicidade.

(4) não é a felicidade privada (seriam empíricos)

(5) não é o sentimento moral e gosto (gosto é relativo, em relação ao sujeito)

É, antes, (6) a razão.

Rx 6762 Ak XIX: 153. 1772.

O que não pode estar sob uma regra universal da vontade pura é moralmente incorreto. A concordância da ação arbítrio livre com a universalidade da vontade pura é moralidade.

Rx 6765 Ak XIX: 154-155. 1772? 1778?

É moralmente impossível a ação cuja intenção, considerada como regra universal, se contradiria necessariamente a si mesma e a de outros.

A intenção de se comportar em suas ações em conformidade ao principio universal das regras é moral. Se a vontade está de modo geral submetida à forma do entendimento. 
Immanuel Kant

Die treibende Kraft des Verstandes beruht darauf, daß er sich an sich selbst allen principiis der Handlungen wiedersetzt, den Gebrauch der regeln unmoglich machen.

Rx 6796. Ak XIX: 163-164. 1773-1775? 1772?

Die Sittlichkeit beruht auf der Regel der Handlungen aus dem Gesichtspunkte (station) des allgemeinen theilnehmers oder Stellvertreters:

1. des theilnehmers der Natur in ansehung seiner selbst,

2. des theilnehmers der freyheit in Ansehung andrer. Im letzteren falle entweder des Stellvertreters der Willkühr anderer oder der Wohlfarth derselben.

Die allgemeinheit ist entweder der Eigenschaft oder der Dinge, welche eine Gewisse Eigenschaft haben. Universalitas interna oder externa. Moralisches Gefühl ist das, wodurch die (allgemeinen obiectiven ) principia der Beurtheilung zu subiectiven der Entschließung werden, also die absolute Regeln zu maximen.

Die freyheit ist unabhängigkeit von triebfedern, mithin auch von Gefühlen. Daher kan nie ein Gefühl seyn, was nothwendig durch die Vernunft, in so fern sie durch die allgemeinheit der Regeln die Willkühr bestimt. Logisch ist die Vernunft der Grund der Regel. Was im allgemeinen gilt, gilt auch im besonderen, was darunter enthalten ist. und practisch überhaupt: Nur dasjenige, was in der Allgemeinheit (im All) gefällt, kan in dem besondern Gefallen, was unter iener enthalten ist. Nur die Allgemeingültigkeit vor die Willkühr in ansehung aller Handlungen ist das, was die freyheit restringirt. Die Lust daran beruht auf der Zusammenstimmung aller Handlungen der Willkühr unter einander durch die Einstimmung mit dem, was das allgemeingültige derselben ist.

Rx 6801. Ak XIX: 165-166. 1773-1775? 1772?

Es ist von der größesten Nothwendigkeit vor der Vernunft, gewisse praktische Regeln als Grundsätze anzunehmen, die absolut necessitiren (categorisch), ohne auf den Bedingungen von Nutzen zu beruhen, z. E. keine Absicht wieder sein eigen Leben zu haben oder seine eigne Persohn nicht andern Absichten aufzuopfern. Denn weil in Bestimmung des Nutzens alles Zufällig ist (die allgemeine Bedingung aber aller Absichten seyn muß daß die Persohn nicht den wesentlichen 
A força motriz do entendimento consiste em este, em si mesmo, se opor a todos os principiis de ações que tornem impossível o uso das regras.

Rx 6796. Ak XIX: 163-164. 1773-1775? 1772?

A moralidade consiste na regra das ações a partir do ponto de vista (station) de um participante universal ou representante universal:

1. Do participante da natureza em relação a si próprio,

2. Do participante da liberdade em relação aos outros. No último caso, ou o representante da liberdade do arbítrio de outros ou do bem-estar dos mesmos.

A universalidade é ou da característica ou das coisas que têm uma certa característica. Universalitas interna ou externa. Sentimento moral é aquilo pelo qual os principia (universais objetivos) do ajuizamento tornam-se [princípios] subjetivos da resolução, portanto, [aquilo pelo qual] as regras absolutas [tornam-se] máximas.

A liberdade é independência de móbiles, também, portanto, de sentimentos. Desse modo, nunca pode ser um sentimento, o que necessariamente pela razão determina o arbítrio, na medida em que ela o determina mediante a universalidade das regras do arbítrio. De uma perspectiva lógica, a razão é o fundamento das regras. O que vale universalmente vale também para o particular, que está contido sob aquele. De uma perspectiva prática em geral: apenas aquilo que agrada na universalidade (no todo) pode [agradar] também nos casos particulares, que estão contidos sob aquela. Apenas a validade universal perante o arbítrio em vista de todas as ações é o que restringe a liberdade. O prazer nisso consiste no acordo de todas as ações do arbítrio entre si mediante a concordância com o que é universalmente válido na mesma.

Rx 6801. Ak XIX: 165-166. 1773-1775? 1772?

É da maior necessidade para a razão assumir certas regras práticas como princípios que necessitam absolutamente (categoricamente) sem basear-se em condições de utilidade, p. ex: não ter nenhum propósito contra sua própria vida ou não sacrificar sua própria pessoa para propósitos dos outros. Pois tudo é contingente na determinação da utilidade (a condição universal de a pessoa não-essencial todas as ações livres e da precedência da 
freyen Handlungen und der Vorzug der freyheit selbst, der den Menschen eines moralischen und inneren Werths fähig macht, dieses ist, daß er durch die thierische triebfedern niemals überwältigt werde, dasienige zu wollen, was ein principium der Handlung wieder sich selbst verräth etc. etc.), so muß diejenige Handlung die unangesehen ihres Nutzens und Schadens das, was eine vorhergehende Handlung Bedingung ist, sich seiner freyheit zu bedienen, die freyheit nothwendig einschränken, folglich die wesentliche Bestimmungen seiner eignen Persohn und das Leben selbst. Wieder diese kan keine Absicht statt finden, ob sie zwar selbst nicht eben die Absicht selber seyn dürfen. Wesentliche Bestimungen sind die, ohne die er entweder kein Mensch oder gar kein freyes wesen seyn würde.

Er soll nicht Absicht haben, die Unwarheit zu reden, weil er als einer, der seinen Sinn bezeichnen kann, die Bedeutung derselben nicht vernichtigen muß. Er soll nicht sich selbst tödten, weil er, wenn er mit sich selbst schaltet, sich als eine Sache betrachtet und die Würde eines Menschen verliert. Er beleidigt andre, wenn er das, was nicht seine Sache ist, als die seinige behandelt. Der Selbstmörder zeigt auch die freyheit in dem Größten wiederstreit wieder sich selbst, mithin in der größten Zerrütung des Eignen Wahnes. Die Menschheit ist heilig und unverletzlich. (so wohl in seiner eignen Persohn als in der anderer. Seine eigne Einwilligung ist hier nichtig, weil man keinen Willen hat um aufzuhören gar etwas zu seyn.) Alle Pflichten bestehen darin daß, nemlich die nothwendigen, bestehen nicht darin, daß wir der Menschen wohlfarth, sondern der Menschheit vorzüge und Würde ehren. Also ist das Recht der Menschheit dasienige, was alle freyheit durch nothwendige Bedingungen einschränkt. Der Mensch kan große Handlungen selbst im Unglüke ausüben aber die Abs und da, wo er das Leben aufopfert, nicht weil er dasselbe haßt, da ist er doch des Lebens werth. Der so sein Leben selbst kleiner schätzt als die Gemächlichkeit des Glüks, der ist des lebens nicht werth.

Alle solche pflichten müssen unabhängig von Pflichten gegen Gott erwogen werden, weil wir diese nur aus der pflichtmäßigkeit der Handlungen an sich selbst urtheilen könen und unsern eignen Gutachten dieses Leben übergeben ist.

Der Selbstmord ist vielleicht nicht so schädlich bey der Erwar(ungeiner-Voraussetzung, es gebe keine andre Welt; aber er ist alsdenn noch scheuslicher. Wie würdet ihr einen freund ansehen, von dem ihr nie sicher wäret, ob er nicht mit dem Selbstmorde umginge? (s Wieder den Selbstmord. So lange der Mensch lebt, hat er immer gelegenheit, gute und selbst heroische tugend auszuüben. Er muß das Leben in dem 
própria liberdade, que torna o homem capaz de um valor moral e interno, é a de que ele nunca seja sobrepujado pelos móbiles animais para querer aquilo que se revela um princípio da ação contra si mesmo, etc. etc.); assim, aquela ação que sem consideração de seu proveito ou malefício aquilo que é uma condição prévia para servir-se de sua própria liberdade deve necessariamente limitar a liberdade, e, por conseguinte, as determinações essenciais de sua própria pessoa e da própria vida. Não pode haver um propósito contra estas, muito embora elas mesmas não possam, de fato, ser o propósito mesmo. Determinações essenciais são aquelas sem as quais ele não seria nem um homem nem um ser livre.

Ele não deve ter como propósito dizer uma inverdade, pois ele, enquanto alguém que pode indicar seu sentido, não pode negar o significado da mesma. Ele não deve suicidar-se, pois fazendo o que bem entende consigo próprio, considera-se como uma coisa e perde a dignidade de um homem. Ele insulta os outros quando trata como sua uma coisa que não é sua. $\mathrm{O}$ suicida mostra a liberdade no maior conflito consigo própria, portanto, no maior desarranjo de sua própria desilusão. A humanidade é sagrada e inviolável. (Tanto em sua própria pessoa quanto na dos outros. O seu próprio consenso é aqui negado, porque não se tem vontade para interromper completamente algo de ser). Todos os deveres eonsistem em que, a saber, os necessários, consistem não em proporcionarmos o bem-estar aos homens, mas antes em honrar e conferir dignidade à humanidade. Portanto, o direito da humanidade é aquilo que limita toda liberdade mediante condições necessárias. O homem pode realizar grandes ações mesmo em desfortuna, e o valor da vida está ali onde ele a sacrifica, mas não por odiá-la. Aquele que rebaixa sua própria vida a uma comodidade da fortuna não é digno dela.

Todos esses deveres têm de ser considerados independentemente dos deveres para com Deus, porque somente podemos julgar estes deveres a partir da conformidade ao dever das ações em si mesmas, e essa vida está consignada à nossa própria avaliação.

Talvez o suicídio não seja tão pernicioso sob a expectiva de pressuposição de que não exista outro mundo; contudo, ele é então ainda mais abominável. Como vocês considerariam um amigo a respeito do qual não estivessem seguros se ele tentaria ou não o suicídio? (Contra o suicídio. Enquanto vive, o homem tem sempre a oportunidade de praticar uma virtude boa e até mesmo heroica. Ele tem de 
Immanuel Kant

größten Elende als die Auffoderung des Schiksals an seine Standhaftigkeit ansehen. )

Rx 6802. Ak XIX: 166-167. 1773-1775; 1772?

Das allgemeine und oberste praktische Gesetz der Vernunft ist: daß die Vernunft die freye Handlungen bestimmen müsse. Wir könen nur ein Wohlgefallen daran haben, so bald wir sie damit zusammen stimmen sehen. Es ist einem vernünftigen Wesen nothwendig, zuvor die freyheit unter das allgemeine Vernunftgesetz zu bringen. Dieses besteht darin, daß die Gesinung der Handlung allgemein genommen mit der freyen willkühr (mit sich selbst) stimme und daß die freyheit zuerst aufhört, eine Ungebundenheit und Gesetzlosigkeit zu seyn. appetite geben keine allgemein stimige Gesetze ; entweder Natur oder Willkühr überhaupt geben den Beziehungsgrund überhaupt an die Hand, in Verhältnis auf welchen eine allgemeine übereinstimung der Handlungen seyn muß. Worauf beruht also das wohlgefallen mit an der Übereinstimung der handlung mit dem, was allgemein genommen nothwendig gefallen würde? und warum gefällt uns diese Allgemeingültigkeit? Woher sind wir bestimmt, das Besondere aus dem allgemeinenabzuleiten? Darum weil wir eben so wohl im Urteil über practischen Urtheil als dem theoretischen die Vernunft als die nothwendige Bedingung derselben ansehn.

Die Handlungen sind nicht richtig, die freyheit ist regellos, wenn sie nicht unter solcher Einschränkung aus der idee des ganzen steht. Sie misfällt uns selbst. Dieses ist die nothwendige Bedingung der practischen form, so wie der raum der intuition.

Rx 6853. Ak XIX: 179. 1776-1779? (extrato parcial)

Die Unterwerfung der freyheit unter die Gesetzgebung der reinen Vernunft. (Aus den allgemeinen Bedingungen der Zweke überhaupt zu den besonderen zu gehen.) Die reine, d. i. von allen (sinnlichen) triebfedern abgesonderte Vernunft hat in Ansehung der freyheit überhaupt gesetzgebende Gewalt, die iedes vernünftige wesen erkennen muß, weil ohne Bedingungen der allgemeinen Einstimmung mit sich selbst in ansehung seiner selbst und anderer gar kein Gebrauch der Vernunft in ansehung ihrer statt finden würde. [...].

Rx 6924. Ak XIX: 208.1778

Die moralitaet besteht in der Unterordnung eines ieden willens unter die Regel allgemein gültiger Zweke. (Die Regel muß seyn, daß die Handlung den allgemein gültigen Zwek zur Bedingung habe.). 
considerar a vida na maior das misérias como o desafio do destino à sua perseverança).

Rx 6802. Ak XIX: 166-167. 1773-1775; 1772?

A lei prática suprema e universal da razão é a seguinte: a razão tem de determinar as ações livres. Nós somente podemos ter complacência com isso a partir do momento em que a vemos concordar com isso. É necessário a um ser racional trazer, antes, a liberdade sob a lei universal da razão. Isso consiste no fato de a intenção da ação tomada universalmente concordar com o livre arbítrio (consigo mesma) e de a liberdade primeiramente deixar de ser sem leis e sem limites. Appetite não dão nenhuma lei universalmente concordante; ou a natureza ou o arbítrio em geral fornece o fundamento de conexão em relação ao qual tem de ocorrer uma concordância universal das ações. Em que, pois, consiste a complacência na concordância da ação com aquilo que, universalmente tomado, agradaria necessariamente? E por que essa universalidade nos agrada? A partir de que somos determinados a derivar o particular do universal? Ora, o motivo é que nós, tanto no juízo prático quanto no juízo teórico, consideramos a razão como sua condição necessária.

As ações não são corretas [e] a liberdade é sem regras quando ela não permanece sob tal limitação a partir da ideia do todo. Nós mesmos a desaprovamos. Isto é a condição necessária da forma prática, assim como para o espaço é a intuição.

Rx 6853. Ak XIX: 179. 1776-1779? (extrato parcial)

A submissão da liberdade à legislação da razão pura (ir das condições universais dos fins em geral às condições particulares). A razão pura, isto é, depurada de todos os móbiles (sensíveis), tem, com vistas à liberdade em geral, um poder legislador que tem de ser conhecido por todo ser racional, pois, sem as condições do acordo universal [de todo ser racional] consigo mesmo em relação a si próprio e aos outros, não existiria nenhum uso da razão em relação a si mesma. [...]

Rx 6924. Ak XIX: 208.1778.

A moralidade consiste na subordinação da vontade de cada um sob a regra de fins universalmente válidos (a regra tem de ser a de que a ação tenha como condição os fins universalmente válidos). 
Immanuel Kant

Rx 7063. Ak XIX: 240.1778

In pragmatischen Lehren ist die freyheit zwar unter Lehren Regeln, aber nicht Gesetzen. Denn die Regel schreibt die Bedingungen vor, unter denen ein beliebiger Zwek erreicht werden kan. Das Gesetz aber bestimt unbedingt die freyheit.

Gesetze der freyheit überhaupt sind die, welche die Bedingungen enthalten, unter denen es allein moglich ist, daß sie mit sich selbst zusammenstimmen: Bedingungen der Einheit des im Gebrauche der freyheit überhaupt. Sie sind also Vernunftgesetze und nicht empirisch oder willkührlich, sondern enthalten absolute praktische Nothwendigkeit. Gesetze sind Regeln der Freyheit überhaupt sind Gesetze der Zufälligen Gebothe. Der freye Wille, der mit sich selbst nach allgemeinen Gesetzen der freyheit Zusammenstimt, ist ein schlechthin Guter Wille.

Rx 7204. Ak XIX: 283-284. 1776-1783 (extrato parcial)

Das Vornehmste problem der moral ist dieses: Die Vernunft zeigt, daß die allgemeine durchgängige Einheit aller Zweke eines Vernünftigen Wesens so wohl in ansehung seiner selbst als andrer, mithin die formale Einheit im Gebrauche unserer freyheit, d. i. die moralität, wenn sie von jedermann ausgeübt würde, die Glükseeligkeit durch freyheit hervorbringen und vom allgemeinen zum besondern ableiten würde und daß umgekehrt, wenn die allgemeine Willkühr jede besondere bestimmen solte, sie nach keinen andern als moralischen principien verfahren könte [...].

(Was kan mich dieses principium (a priori) der allgemeinen Einstimung der freyheit mit sich selbst interessiren? Die freyheit nach principien empirischer Zweke hat keine durchgängige Einstimmung mit sich selbst; ich kan mir daraus nichts zuverläßiges in ansehung meiner selbst vorstellen. Es ist keine Einheit meines willens. Daher sind restringirende Bedingungen des Gebrauchs derselben absolut nothwendig. Moralitaet aus dem principio der Einheit. Aus dem princip der warheit. Daß man sein principium, was man öffentlich bekennen darf, befolgt, also vor jedermann gilt. Vollkommenheit der form nach: die allgemeine Zusammenstimung der freyheit mit den wesentlichen Bedingungen aller Zweke, d. i. Zwekmäßigkeit a priori). 
Rx 7063. Ak XIX: 240.1778.

Em doutrinas pragmáticas, a liberdade está certamente sob doutrinas regras, mas não sob leis. Pois a regra prescreve as condições sob as quais um fim qualquer pode ser alcançado. A lei, contudo, determina a liberdade incondicionalmente.

As leis da liberdade em geral são aquelas que contêm as condições unicamente sob as quais é possível que ela esteja de acordo consigo mesma: condições da unidade no uso da liberdade em geral. Elas são, portanto, leis racionais e não empíricas ou arbitrárias, mas antes contêm necessidade prática absoluta. Leis sãe Regras da liberdade em geral são leis dos mandamentos contingentes. A vontade livre, que concorda consigo mesma segundo leis universais, é uma vontade absolutamente boa.

Rx 7204. Ak XIX: 283-284. 1776-1783. (extrato parcial)

O principal problema em moral é o seguinte: a razão mostra que a unidade completa universal de todos os fins de um ser racional em relação tanto a si próprio quanto aos outros, portanto a unidade formal no uso de nossa liberdade, isto é, a moralidade, caso fosse exercida por todos, produziria a felicidade através da liberdade e derivaria do universal para o particular, inversamente, a razão também mostra que, se o arbítrio universal devesse determinar cada arbítrio em particular, ele somente poderia proceder segundo princípios morais. $[\ldots]$

(Em que pode me interessar esse principium (a priori) da concordância universal da liberdade consigo própria? A liberdade segundo princípios de fins empíricos não tem uma concordância completa consigo mesma, por meio disso, eu não posso me representar nada confiável relativamente a mim mesmo. Não há unidade de minha vontade. Portanto, as condições restritivas do uso da mesma são absolutamente necessárias. Moralidade a partir do principio da unidade. Do principio da verdade. Que sigamos o principium que podemos reconhecer publicamente, portanto, que vale para todos. Perfeição segundo a forma: o acordo universal da liberdade com as condições essenciais de todos os fins, isto é, conformidade a fins a priori.) 
Immanuel Kant

\section{2) Esboços da concepção crítica de liberdade}

Rx 3872. Ak XVII: 319-320. 1764-1768? (1771??) (extrato parcial)

[...] Die Freyheit besteht in dem Vermögen, unabhängig von äußern bestimmenden Gründen nach intellectualer Willkühr handeln zu können. [...] Seine Willkühr als Thier wird wirklich immer bestimmt durch stimulos; aber sein Wille ist doch frey, so fern seine Vernunft vermögend ist, diese Bestimungen der Willkühr zu ändern. Warum daß die Vernunft bisweilen nicht thue und der Mensch nicht nach dem intellectualen willen handele, ist unbekant $[\ldots]$.

Rx 3928 Ak XVII: 350-351. 1769. (extrato parcial)

[...] Es ist aber eben so unmöglich, sich eine Reihe subordinirter Gründe vorzustellen, die keinen Anfang hat, als sich zu concipiren, wie sie anfange. Indessen ist der Satz: alles, was geschieht, hat einen determinirenden Grund, dieser Satz, der eine unendliche Reihe nothwendig macht, das principium der Form aller Unserer Vernunfturtheile über die realverknüpfung. Der Satz aber: alle Reihe subordinirter Dinge und alle successive Reihe hat ein erstes, ist ein synthetischer Satz, der mehr von den Grentzen unseres Verstandes, als von dem obiect der Erkenntnis abstrahirt ist.

Das erste in der Reihe der Ursachen ist immer die freye Willkühr. $\mathrm{Da} \beta$ diese keinen bestimmenden Grund habe, ist ein empirischer Satz, aber in so fern ungewi $\beta_{;}$allein seine Gewisheit hängt davon $a b$, daß sonsten gar kein erstes seyn könne [...].

Rx 4219. Ak XVII: 462. 1769-1770 (extrato parcial)

Die Schwierigkeit die menschliche Freyheit zu begreifen, liegt darin, da $\beta$ das subiect dependent ist und doch independent von andern Wesen handeln soll [...].

Rx 4225. Ak XVII: 464. 1769-1770?; (1773-1777?) (extrato parcial)

Da die Freyheit eine vollständige selbstthätigkeit des Willens ist, ohne durch stimulos oder durch irgend etwas anderes, was das subiect afficirt, bestimmt zu seyn, so kommt es bey ihr nur auf die Gewisheit der Persohnlichkeit an: daß sie nemlich (sich) bewust sey sie handle aus eigner Willkühr, sie handle der Wille sey thatig und nicht leidend, weder durch stimulos noch durch fremde Eindrüke. 


\section{2) Esboços da concepção crítica de liberdade}

Rx 3872. Ak XVII: 319-320. 1764-1768? (1771??). (extrato parcial)

[... A liberdade consiste na faculdade de poder agir segundo o arbítrio intelectual independentemente de fundamentos determinantes externos. [...]. Seu arbítrio [do homem], enquanto animal, é de fato determinado sempre segundo stimulos; mas sua vontade é livre na medida em que sua razão é capaz de mudar essas determinações do arbítrio. É desconhecido por que, porém, a razão eventualmente não atua e o homem não age segundo a vontade intelectual $[\ldots]$.

Rx 3928 Ak XVII: 350-351. 1769. (extrato parcial).

[...] É, do mesmo modo, tão impossível representar uma série de fundamentos subordinados que não tem início quanto conceber como ela começa. Contudo, a proposição "tudo o que acontece tem um fundamento determinante", ou seja, a proposição que torna necessária a série infinita é o principium da forma de todos os nossos juízos da razão sobre conexões reais. Contudo, a proposição "toda a série de coisas subordinadas e toda a série sucessiva têm um primeiro", é uma proposição sintética, que é abstraída mais dos limites de nosso entendimento do que do objeto do conhecimento.

O primeiro na série causal é sempre o livre arbítrio. Que este não tenha nenhum fundamento determinante é uma proposição empírica, mas, nessa medida, incerta ${ }_{i}$ porém, sua certeza depende do fato de que, do contrário, não poderia haver um primeiro [...].

Rx 4219. Ak XVII: 462. 1769-1770. (extrato parcial)

A dificuldade em compreender a liberdade humana consiste no fato de o sujeito ser dependente e, não obstante, dever agir independentemente de outros seres [...].

Rx 4225. Ak XVII: 464. 1769-1770?; (1773-1777?). (extrato parcial)

Visto que a liberdade é a completa autoatividade da vontade de ser determinada sem stimulos ou qualquer outra coisa que afete o sujeito, ela então depende apenas da certeza da personalidade, a saber, de ser consciente de que ela age pelo próprio arbítrio, de que ela age de que a vontade é ativa e não passiva, nem por meio de stimulos nem por 
Immanuel Kant

Sonst müste ich sagen: ich bin getrieben oder bewegt, so oder so zu handeln, welches so viel heißt als: ich bin nicht handelnd, sondern leidend. Wenn Gott die Bestimmungen der Willkühr regirt, so handelt er; wenn die reitze der Dinge sie nothwendig bestimmen, so nöthigen $\mathrm{sie}_{;}$in beyden Fällen entspringt die Handlung nicht aus mir, sondern ich bin nur das mittel einer andern Ursache.

In der Sinnenwelt ist nichts begreiflich, als was durch vorhergehende Gründe necessitirt ist. Die Handlungen der freyen willkühr sind phaenomena; aber ihre Verknüpfung mit einem selbstthatigen subiect und mit (dem Vermögen) der Vernunft sind intellectual, demnach kan die Bestimmung der freyen Willkühr den legibus sensitivis nicht submittirt werden $[\ldots]$.

\section{Rx 4227 Ak XVII: 466. 1769-1770? (1769?) (1764-1768?) (extrato parcial)}

Wären die Menschen vollig intellectual, so wären alle ihre Handlungen thatig determinirt, aber doch frey, und würden nur in Ansehung der veranderlichen Gelegenheiten zufallig seyn. Es würden ihnen auch diese handlungen imputirt werden können zusamt den Belohungen, ob sie gleich geschopfe eines höhern wesens wären. Denn sie wären als selbstthetige principien und als würdige Gegenstände seiner Gütigkeit anzusehen. Wären sie vollig sinnlich, so wären ihre Handlungen allein passiv determinirt, ihnen könte nichts imputirt werden, und sie würden keiner Belohnungen und Bestrafungen fähig seyn. Nun sind sie zum Theil sinnlich, zum Theil intellectual, doch so, daß die Sinnlichkeit freylich das intellectual nicht passiv machen kan, Aber das intellectuale die Handlungen auch nicht anders als durch ein gewisses Maas des Ubergewichts über die Sinnlichkeit überwinden kan. also ist der Mensch weder active noch passive determinirt; und da die Sinnlichkeit so wohl als die Stärke der Vernunft von den Umständen abhängt, so dependiren seine Handlungen zum Theil von den Umständen, zum Theil von dem Gebrauche seiner Vernunft und können ihm nicht ganzlich imputirt werden. Er ist frey, wenn man es aufs genaueste nimt, allein die Möglichkeit, etwas Gutes zu thun, worin die Freyheit eigentlich besteht. Allein ob die Handlung wirklich aus diesem principio oder dem sensitiven entspringe, kommt auf die conditionen an.

Rx 4228. Ak XVII: 467. Por volta de 1770

Wir sehen uns durch das Bewustseyn unsrer Persöhnlichkeit in der intellectualen Welt und finden uns frey. Wir sehen uns durch unsre Abhängigkeit von Eindrüken in der Sinnenwelt und finden uns 
impressões alheias. Do contrário, eu teria de dizer que sou movido ou impelido a agir de tal ou tal modo, o que significa dizer que não sou agente, mas, antes, paciente. Se Deus rege as determinações do arbítrio, então ele age; se os estímulos das coisas as determinam necessariamente, então eles necessitam. Em ambos os casos, a ação não surge de mim, mas antes sou apenas o meio de uma outra causa.

No mundo sensível somente é apreensível o que é necessário por meio de razões precedentes. As ações do livre arbítrio são phaenomena, mas a sua conexão com um sujeito autoativo e [a conexão] com a (faculdade) da razão são intelectuais; por conseguinte, a determinação do livre arbítrio não pode ser submetida às legibus sensitivis [...].

\section{Rx 4227 Ak XVII: 466. 1769-1770? (1769?) (1764-1768?). (extrato parcial)}

Se os homens fossem completamente intelectuais, então todas as suas ações seriam determinadas ativamente, mas livremente, e seriam contingentes apenas em relação às circunstâncias mutáveis. Essas ações também poderiam lhes ser imputadas em conjunto com recompensas, ainda que fossem criações de um ser supremo. Pois elas deveriam ser consideradas como princípios autosubsistentes e como objetos dignos de sua bondade. Se os homens fossem completamente sensíveis, então suas ações seriam determinadas apenas passivamente ${ }_{i}$ nada lhes poderia ser imputado, e eles não seriam capazes de recompensas e punições. Ora, os homens são em parte sensíveis e em parte intelectuais, de modo que a sensibilidade certamente não pode tornar passivo o intelectual, e o intelectual tampouco pode empreender ações de outro modo senão através de um certo grau de superação sobre a sensibilidade. Portanto, o homem não é determinado nem ativa, nem passivamente $e_{i}$, visto que tanto a sensibilidade quanto as forças da razão dependem de circunstâncias, então as ações do homem dependem em parte das circunstâncias e em parte do uso de sua razão, e não podem ser-lhes completamente imputadas. Ele é livre quando se considera apenas e exatamente a possibilidade de fazer algum bem, no que propriamente consiste a liberdade. Contudo, se a ação surge realmente desse princípio ou de princípios sensíveis, é algo que depende de condições [...].

Rx 4228. Ak XVII: 467. Por volta de 1770.

Mediante a consciência de nossa personalidade, vemo-nos no mundo intelectual e nos consideramos livres. Mediante nossa dependência de impressões, vemo-nos no mundo sensível e nos consideramos 
Immanuel Kant

determinirt. Unsere Anschauungen der Körper gehören alle zur Sinnen welt ${ }_{i}$ demnach stimen die Erfahrungen mit den Gesetzen derselben von determinirenden gründen. aber unsre intellectuale Anschauungen vom freyen Willen stamen nicht mit den Gesetzen der phaenomenorum.

Rx 4725. Ak XVII: 688. 1773-1775; (1778?)

Der Practische Begrif der Freyheit ist, der zureicht, um Handlungen nach regeln der Vernunft zu thun, der also dieser ihren imperativen die Gewalt giebt; der speculative oder vernünftelnde Begrif der Freyheit ist, der zureicht, um Handl freye Handlungen nach der Vernunft zu erklären. Letzterer ist unmoglich, weil es das Ursprüngliche im derivativo ist.

Rx 5435. Ak XVIII: 181. 1778-1783

Der Wille ist ein Vermogen, nach der Vorstellung einer Regel als Gesetztes zu handeln. Vermögen nach der Zweke. stimuli sind Lust, die vor dem Gesetz vorhergeht. independentia a stimulis ist, wo das Gesetz vor der Lust vorhergeht. (arbitrium purum.) (s Freyheit ist caussalitaet der reinen Vernunft in Bestimmung der Willkühr.)

Rx 5436. Ak XVIII: 181. 1778-1783

Freyheit ist das Vermögen, nur durch Vernunft determinirt zu werden, und nicht blos mittelbar, sondern unmittelbar, also nicht durch Materie, sondern form des Gesetzes. Also moralisch.

Rx 5440. Ak XVIII: 182. 1776

Die Freyheit, so fern sie ein Vernunftbegrif ist, ist unerklärlich (auch nicht obiectiv); so fern sie ein Begrif von der thatigkeit und causalitaet der Vernunft selbst ist, kann sie zwar auch nicht als ein erstes princip erklart werden, ist aber ein Selbstbewustseyn a priori.

Rx 6860. Ak XIX: 183. 1778? 1780-1783?

Wir können uns keinen Begrif davon machen, wie eine bloße form der Handlungen könne die Kraft einer triebfeder haben. Indessen muß dieses doch seyn, wenn moralität statt finden soll, und Erfahrung bestätigt es. Diese Formale causalität als wirkend ist nicht unter Erscheinungen bestimmt. Sie ist also jederzeit neu, ungeachtet alles dessen, was geschehen seyn mag. Es ist blos unser Selbst und 
determinados. Nossas intuições de corpos pertencem, todas, ao mundo sensivel $_{i}$ portanto, as experiências concordam com as leis do mesmo por fundamentos determinados. Contudo, nossas intuições intelectuais da vontade livre não concordam com as leis dos phaenomenorum.

Rx 4725. Ak XVII: 688. 1773-1775; (1778?).

O conceito prático de liberdade é aquele que basta para realizar ações segundo regras da razão, e que, portanto, dá poder aos imperativos desta. O conceito especulativo ou sofístico de liberdade é aquele que basta eçẽ para explicar ações livres segundo a razão. Este último é impossível, pois ele é o originário im derivatio.

Rx 5435. Ak XVIII: 181. 1778-1783.

A vontade é uma faculdade de agir segundo a representação de uma regra como lei. Faculdade dos fins. Stimuli são um prazer que precede a lei. Independentia a stimulis há onde a lei precede o prazer. (arbitrium purum) (Liberdade é a causalidade da razão pura na determinação do arbítrio).

Rx 5436. Ak XVIII: 181. 1778-1783.

Liberdade é a faculdade de ser determinado apenas pela razão e não meramente de modo mediato, mas sim imediatamente, portanto, não pela matéria, mas antes pela forma da lei, moralmente, portanto.

Rx 5440. Ak XVIII: 182. 1776.

A liberdade, na medida em que é um conceito racional, é inexplicável (também não é objetivo); na medida em que ela mesma é um conceito da atividade e causalidade da razão, certamente não pode ser esclarecida como um primeiro princípio, mas é uma autoconsciência a priori.

Rx 6860. Ak XIX: 183. 1778? 1780-1783?

Nós não podemos constituir um conceito de como uma mera forma das ações possa ter a força de um móbil. Contudo, tem de ser assim, se deve existir moralidade, e a experiência o confirma. Esta causalidade formal como atuante não é determinada sob fenômenos. Portanto, ela é sempre nova, a despeito de tudo aquilo que possa ocorrer. Quem determina a ação é meramente nosso eu e não uma 
Immanuel Kant

keine fremde Anlage, keine Kette der Erscheinungen, die empirisch bestimt ist, welche die Handlung bestimt. Die apperception seiner selbst als eines intellectuellen wesens, was thätig ist, ist freyheit.

\section{3) Divisão da filosofia prática em ética e direito}

Rx 6492. Ak XIX: 27-28 1764-1770

Externe moraliter cogor per motiva iuris, interne per motiva Ethica. vera coactio Moralis est externa secundum motiva iuris. Coactio internaest imperium in semet et subiectiva.

Rx 6494. Ak XIX: 28-29. 1764-1770 (extrato parcial)

Cogi non potest moraliter, nisi per motiva moralia qvatenus potest sensu morali.e. g. Cogo aliqvem moraliter, si sub conditione vel Etbica vel iuris, e.g. miseriam aliorum alicui sub oculos ponendo vel datam fidem in animum revocando, impello.

Rx 6666. Ak XIX: 127-128. 1769-1770? 1772? (extrato parcial)

[...] Iede freye Handlung ist recht, ausser so ferne der Wille anderer wiedersteht und die Handlung nach der Regel des Gemeinschaftlichen Willens unmöglich macht [...].

Rx 6667. Ak XIX: 128. 1769-1770? 1772 (extrato parcial)

Recht ist (zwischen zweyen), was durch ihren gemeinschaftlichen Willen möglich ist. (Was durch denselben nothwendig ist, heißt Schuldigkeit.) Ein Recht hat der einer in ansehung des Andern (affirmative), in so fern wenn sein privatwille als einerley mit dem gemeinschaftlichen angesehen werden kan. Die Nothwendigkeit einer Handlung um der allg Regel des Rechts willen heißt formale Schuldigkeit, um des Rechts der andern willen aber materiale Schuldigkeit. Die Regel, die dem gemeinschaftlichen Willen überhaupt nothwendiger weise anhängt, wird gefunden, indem die condition des Willens gesucht wird, welche nothwendig ist, damit sie er allgemein gültig sey. Man kan die Verhältnisse des Rechts mit denen der Korper vergleichen. Ein ieder Körper ist gegen alle andere in Ruhe, ausser so fern er durch andere bewegt wird, und eben so hat iederman gegen andere Pflichten der Unterlassung, ausser so fern andere entweder mit ihm einen Einstimigen Willen machen oder seinen Zustand wieder seinen Willen verändern. Actio est aequalis reactione. So viel ein großer Korper auf den kleinen wirkt, so viel dieser auf den groosen zurük. Der gemeinschaftliche 
disposição alheia, nenhuma cadeia de fenômenos que é empiricamente determinada. Liberdade é a apercepção de si mesmo como um ser intelectual que é ativo.

\section{3) Divisão da filosofia prática em ética e direito}

Rx 6492. Ak XIX: 27-28 1764-1770

Eu sou coagido de forma externa moralmente através de motivos do direito, e de forma interna através de motivos éticos. A verdadeira coerção moral é externa segundo motivos do direito. A coerção interna é o domínio sobre si mesmo e é subjetiva.

Rx 6494. Ak XIX: 28-29. 1764-1770 (extrato parcial)

Não é possível ser moralmente coagido senão através de motivos morais. Por exemplo, eu coajo alguém moralmente quando eu o impilo sob uma condição ética ou jurídica, por exemplo, quando the disponho diante dos olhos a miséria de outrem ou recordo-lhe alguma promessa dada.

Rx 6666. Ak XIX: 127-128. 1769-1770? 1772? (extrato parcial)

[...] Toda ação livre é correta a não ser na medida em que se opõe à vontade dos outros e torna impossível a ação segundo a regra da vontade comunitária [...].

Rx 6667. Ak XIX: 128. 1769-1770? 1772 (extrato parcial)

Direito [...] é o que é possível através de sua vontade comunitária (aquilo que é necessário através desta chama-se dever). Alguém quem tem um direito em relação a outrem (afirmativo) medida em que quando sua vontade privada pode ser considerada idêntica à vontade comunitária. A necessidade de uma ação por virtude da regra univ do direito chama-se dever formal, e por virtude do direito de um outro, porém, dever material. A regra que se liga de modo necessário à vontade comunitária em geral é encontrada ao se buscar a condição da vontade, que é necessária para que ela essa vontade seja universalmente válida. Pode-se comparar as relações do direito com aquelas dos corpos. Cada corpo está em repouso em relação aos demais a não ser na medida em que é movimentado por outros, e, do mesmo modo, cada um tem um dever de omissão para com outrem a não ser na medida em que outros ou bem ponham sua vontade em concordância 
Immanuel Kant

Schwerpunkt, d. i. der gemeinschaftliche Wille, ist vor und nach der Handlung einerley $[\ldots]$.

Rx 6670. Ak XIX: 129.1769-1770? (1770-1771?) (1764-1768?)

Die ethische Regel lautet so: thue das, was dir dounket einem andern gut zu seyn; die des Rechts lautet so: thue das, was mit der allgemeinen Regel der Handlungen zusammenstimmt, in so fern ieder thut, was ihm selbst gut dünkt.

Rx 6672. Ak XIX: 129-130. 1769-1770? (1764-1768?)

Was nach der Regel des all reinen Willens allgemein genomen moglich ist, ist recht [...]. (s Die Regel der privat Neigung ist eigenützig und nicht moralisch. )

Die Allgemein Gültige Regel der Neigungen ist eine Regel der Glükseeligkeit; denn daß allgemeine aller neigungen ist Annehmlichkeit und deren abstractum Gloukseeligkeit. Wer Unrecht thut, verdient aller Menschen feindschaft; wer ungütig ist, kan so glükseelig seyn, als er sich selbst machen kan, aber ist keines Menschen Liebe fähig würdig.

Wenn alle Menschen und Regierungen nach regeln des Rechts geschähen,so würden die Pflichten der Gütigkeit unnothig seyn.

Die Urtheile über Recht und Schuldigkeit betrachten die Regeln der voluntatis purae, sind also die leichtesten; die der Gütigkeit gehen auf Neigungen, Verhältnisse des Wohlbefindens und sind schweer. schlecht und recht ist die praecisio iustitiae.

Mit den motivis iuris könen gar keine andere als auch motiva iuris, niemals aber die der Gütigkeit verglichen werden. Diese aber könen mit pragmatischen verglichen und durch sie superponderirt werden.

Rx 6715 Ak XIX: 139. 1772? (1771?)) (extrato parcial)

Die moralische gesetze, weil sie vor den freyen willen überhaupt gelten, so sind sie auch gültig vor den menschlichen; allein die reine regeln der Pflicht, applicirt auf die Schwäche der Menschlichen Natur, erleiden zwar keine Ausnahmen oder milderung (diese würde auch zum Schaden der Menschlichen Natur und anderer Menschen gereichen), aber sie dienen durch das Bewustseyn der eignen Ungerechtigkeit, nicht blos aus Gütigkeit, sondern aus Gründen des Rechts nicht alle Ansprüche zu machen, welche sonst nach den strengen Befugnissen der Gerechtigkeit von einer Persohn, die selbst gerecht wäre, zu machen 
com ele, ou bem alterem seu o estado contra sua vontade. Actio est aequalis reactione. Tanto mais um corpo grande afeta um pequeno, tanto mais este reage ao maior. O centro de gravidade comunitário, isto é, a vontade comunitária, é idêntico antes e depois da ação [...].

Rx 6670. Ak XIX: 129.1769-1770? (1770-1771?) (1764-1768?)

A regra ética diz: "faça o que lhe parece ser bom a outrem"; a regra do direito diz: "faça o que concorda com a regra universal das ações, na medida em que cada um faz aquilo que lhe parece ser bom para si próprio".

Rx 6672. Ak XIX: 129-130. 1769-1770? (1764-1768?).

O que é possível segundo a regra da vontade uniw pura considerada universalmente é correto. [...] (A regra da inclinação privada é egoísta e não moral).

A regra universalmente válida das inclinações é uma regra da felicidade, pois o universal de todas as inclinações é o agradável e, seu abstractum, a felicidade. Quem age incorretamente merece a inimizade de todos os homens; quem não é bondoso pode ser tão feliz quanto possa conseguir, mas não é digno capaz do amor dos homens.

Se todos os homens e governos fossem conformes a regras do direito, então os deveres da bondade seriam inúteis.

Os juízos sobre direito e dever consideram as regras da voluntatis purae, e são, portanto, os mais fáceis; aqueles sobre a bondade tratam de inclinações, relações de bem-estar e são difíceis. A praecisio iustitae é direta e reta.

Não é possível comparar com os motivis iuris com outros motivos nenhum outro a não ser também motiva iuris, mas nunca aqueles de bondade. Estes, contudo, podem ser comparados com os pragmáticos e ser sobrepostos por eles.

Rx 6715 Ak XIX: 139. 1772? (1771?)) (extrato parcial)

As leis morais, visto que elas valem para a vontade livre em geral, são também válidas para a vontade humana; contudo, as regras puras do dever, aplicadas às fraquezas da natureza humana, certamente não permitem nenhuma exceção ou atenuação (estas ocorreriam também para prejuízo da natureza humana e dos outros homens), mas elas, mediante a consciência da própria injustiça, não meramente pela bondade, mas antes a partir de fundamentos do direito, não servem para levantar todas as pretensões que, do contrário, teriam sido levan- 
Immanuel Kant

seyn würden. e.g. Staatsverfassung. Denn es ist nicht zu verlangen, daß alles gerecht sey gegen uns, wenn wir es nicht mit gewisheit gegen andre seyn. Zweytens: die religion zu den Pflichten hinzuzuthun.

Rx 6767. Ak XIX: 155. 1772? 1769? 1764-1768? (extrato parcial)

Moralitaet (g objectiv) ist die freyheit nach (g unter) Gesetzen.

Die Freyheit unter inneren Gesetzen ist ethisch obligation äußeren ist juridisch obligation

Gesetz ist die Einschrankung der Freyheit durch allgemeine Bedingungen der Einstimmung derselben mit sich selbst.

Freyheit, die ohne Gesetz gut ist, ist ursprünglich.

(Die Übereinstimung beruht entweder auf der Einheit des Zweks oder Einheit der bricht ab.).

1. handle Gesetzmäßig ohne Zwang.

2. Übe Zwang aus, aber nach Gesetzen.

3. Unterwirf die freyheit dem Zwang der Gesetze. 